\title{
Image Analysis Characterization of Modern Pipe Steels Structures
}

\author{
A.A. Kazakov, ${ }^{*}$ D.V. Kiselev, ${ }^{*}$ E.I. Kazakova, ${ }^{*}$ and L.S. Chigintsev * \\ * Steel and Alloys Department, Saint-Petersburg State Polytechnical University, Russia, Saint- \\ Petersburg, Polytechnicheskaya, 29, 195251
}

Russian standard GOST 5640 describes methods to estimate the degree of ferrite-pearlite banding using a scale matching method (bar charts), designed according to the principle of an increasing number of pearlite bands considering their continuity and the aspect ratio of the ferrite grains.

The next generation of pipe steels have a ferrite-bainite microstructure with significantly finer grain size. Because of this change, current research must provide a new set of scales to evaluate such constituents. These new scales utilize the same principles as the existing scales in GOST 5640.

In order to reduce the bias of banding measurements, an automatic method was developed for the Thixomet image analyzer. This method follows the procedure in ASTM E 1268 and utilizes a test grid of parallel lines. Compared to ASTM E 1268 where banding is described in a verbal way, the new proposed method calculates the banding criteria using ideas developed by S. A. Saltykov [1]. The rating, which is similar to that of GOST 5640, is assigned according to the value of the Saltykov banding criteria and the anisotropy of ferrite grains.

Final rolling with accelerated cooling is utilized to produce modern pipe steel plates. These plates are free of microstructural banding which is detrimental to mechanical properties. These steels, however, do exhibit microstructure anisotropy. Stereological methods based on structural element recognition cannot be applied to such structures because of the complex bainitic morphology. To solve the problem for these steels, a method to estimate structural anisotropy was developed based upon the principle of texture analysis using a gray level co-occurrence matrix [2]. The coefficient defined using our method distinctly characterizes the structural anisotropy of such steels.

For pipe steel compositions, processing can produce different bainitic morphologies, some of which have a detrimental effect on the steel's mechanical properties. An etching method that gives the ability to identify, analyze and measure detrimental coarse lath morphology bainite was developed and is shown in Fig. 1. This analysis is also performed automatically, without operator influence, using the Thixomet image analyzer. The quantitative impact of coarse lath morphology bainite upon the pipe steel's mechanical properties was determined and is shown in Fig. 2.

A method of image analysis based on Fourier transform to quantitatively describe the degree of centerline segregation in plate steels was developed. Another method for characterization of centerline segregation was also developed and is based on plotting and subsequent analysis of a microhardness distribution curve measured across the centerline. We have shown that the newly developed coefficient of microstructural heterogeneity is a distinct segregation characteristic for all major alloying and impurity elements, and can be treated as an objective quantitative characteristic of centerline segregation development. 
Thereby, as a result of the research work defined herein, methods were developed to provide a quantitative description of microstructural heterogeneity for all types of modern pipe steels. Examples of the application of these methods for prediction and interpretation of the mechanical properties of different strength level steel grades are provided.

\section{References:}

[1] S.A. Saltykov, Stereometric Metallography, 2d ed., Metallurgizdat, Moscow, 1958.

[2] R.M. Haralick, Proceedings of the IEEE. 67 (1979) 786.

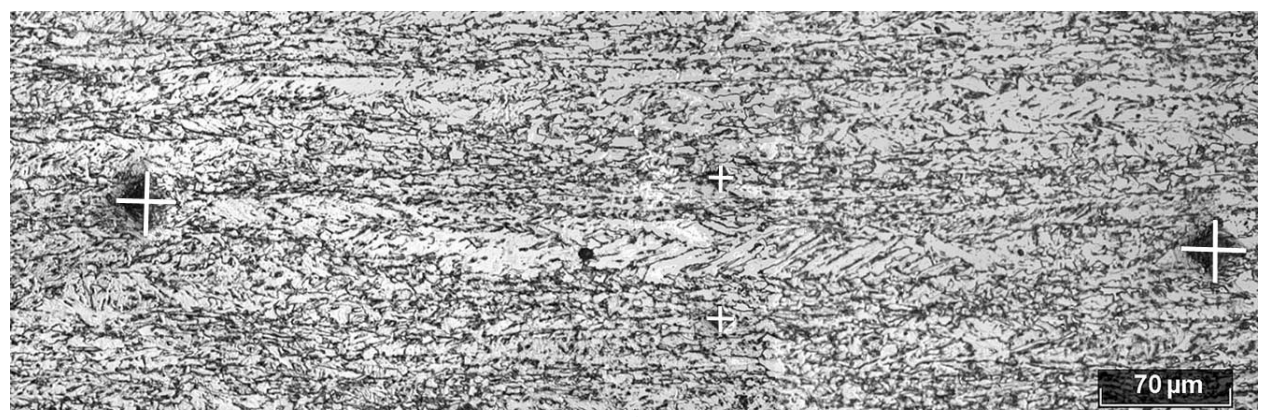

a)

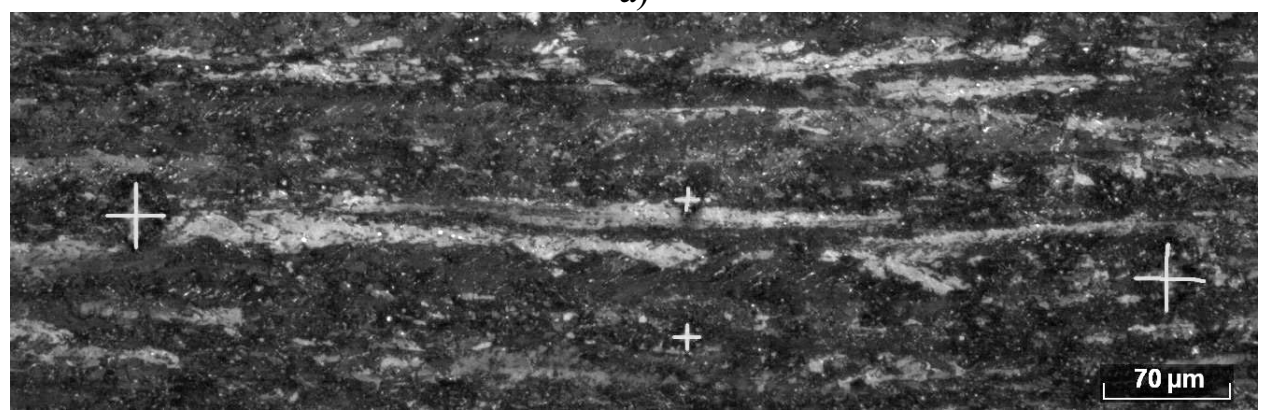

b)

FIG. 1. Microstructure of pipe plate etched with $3 \%$ nital, bright field (a) and $\mathrm{Na}_{2} \mathrm{~S}_{2} \mathrm{O}_{5}$-based solution, polarized light (b).
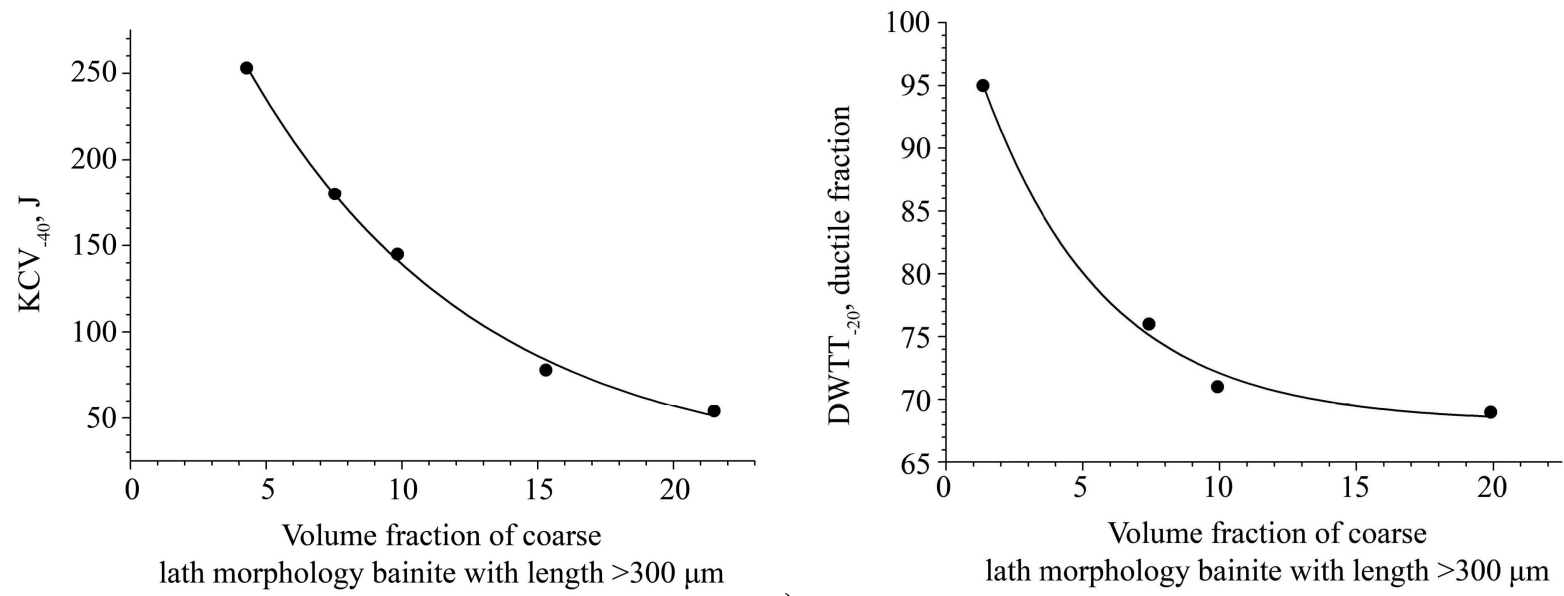

a)

b)

FIG. 2. Mechanical properties versus coarse lath morphology bainite volume fraction: a) impact toughness at $-40^{\circ} \mathrm{C}$; b) fraction of ductile fracture after drop weight tear test at $-20{ }^{\circ} \mathrm{C}$. 